CRYSTALLOGRAPHIC COMMUNICATIONS

ISSN 2056-9890

Received 10 July 2016

Accepted 25 July 2016

Edited by M. Weil, Vienna University of

Technology, Austria

Keywords: crystal structure; niobium; fluoride; $\mathrm{SnF}_{4}$ type.

CCDC reference: 1496052

Supporting information: this article has supporting information at journals.iucr.org/e

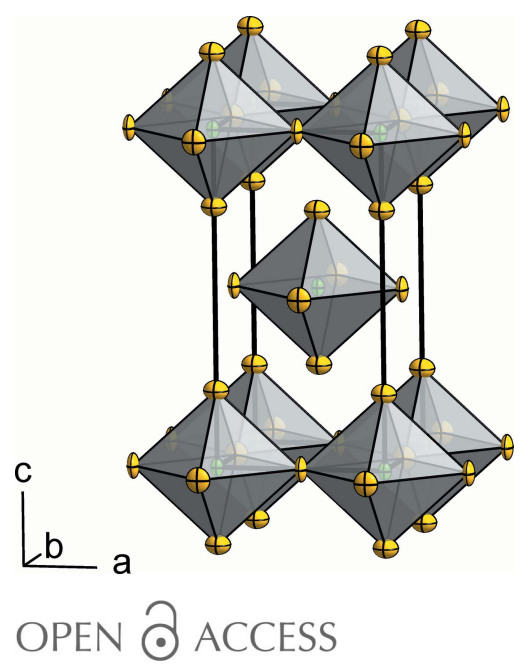

\section{Redetermination of the crystal structure of $\mathrm{NbF}_{4}$}

\author{
Jascha Bandemehr, Matthias Conrad and Florian Kraus*
}

Anorganische Chemie, Fachbereich Chemie, Philipps-Universität Marburg, Hans-Meerwein-Strasse 4, 35032 Marburg, Germany.*Correspondence e-mail: florian.kraus@chemie.uni-marburg.de

Single crystals of $\mathrm{NbF}_{4}$, niobium(IV) tetrafluoride, were synthesized by disproportionation of $\mathrm{Nb}_{2} \mathrm{~F}_{5}$ at $1273 \mathrm{~K}$ in a sealed niobium tube, extracted and studied by single-crystal X-ray diffraction. Previous reports on the crystal structure of $\mathrm{NbF}_{4}$ were based on $\mathrm{X}$-ray powder diffraction data and the observed isotypicity to $\mathrm{SnF}_{4}$ [Gortsema \& Didchenko (1965). Inorg. Chem. 4, 182-186; Schäfer et al. (1965). J. Less Common Met. 9, 95-104]. The data obtained from a single-crystal X-ray diffraction study meant the atomic coordinates could now be refined as well as their anisotropic displacement parameters, leading to a significant improvement of the structural model of $\mathrm{NbF}_{4}$. In the structure, the $\mathrm{Nb}$ atom is octahedron-like surrounded by six $\mathrm{F}$ atoms of which four are bridging to other $\mathrm{NbF}_{6}$ octahedra, leading to a layer structure extending parallel to the $a b$ plane.

\section{Chemical context}

The first synthesis of niobium tetrafluoride was reported by Schäfer and co-workers by reduction of niobium pentafluoride with niobium metal (Schäfer et al., 1964). According to Gortsema and coworker, a reduction of $\mathrm{NbF}_{5}$ with silicon is seemingly the best way to obtain pure $\mathrm{NbF}_{4}$ (Gortsema \& Didchenko, 1965). The obtained products were reported as dark-blue or black powders, respectively (Gortsema \& Didchenko, 1965, Schäfer et al., 1964). However, we obtained green $\mathrm{NbF}_{4}$ single crystals among a green powder. $\mathrm{NbF}_{4}$ is moisture sensitive and deliquesces to a brown suspension. In aqueous medium a brown precipitate is formed. It is reported to be soluble in hydrochloric acid, sulfuric acid or hydrogen fluoride (Schäfer et al., 1965). The compound disproportionates under vacuum above $623 \mathrm{~K}$ to $\mathrm{NbF}_{5}$ and a fluoride of which the compositions were reported as $\mathrm{NbF}_{2.37}$ (Schäfer $e t$ al., 1965) or $\mathrm{NbF}_{3}$ (Gortsema \& Didchenko, 1965). In a sealed niobium ampoule $\mathrm{NbF}_{4}$ disproportionates at $825 \mathrm{~K}$ to $\mathrm{NbF}_{5}$ and $\mathrm{Nb}_{2} \mathrm{~F}_{5}$ (Chassaing \& Bizot, 1980). Infrared spectra (Dickson, 1969), UV/Vis-spectra (Chassaing \& Bizot, 1980) and powder X-ray patterns are available for $\mathrm{NbF}_{4}$ (Gortsema \& Didchenko, 1965, Schäfer et al., 1965). Magnetic measurements show that $\mathrm{NbF}_{4}$ orders antiferromagnetic in contrast to the other niobium tetrahalides which are reported to be diamagnetic (Chassaing \& Bizot, 1980).

\section{Structural commentary}

The lattice parameters obtained by our single-crystal structure determination of $a=4.0876$ (5), $c=8.1351$ (19) $\AA$ are in good agreement with those obtained previously from powder X-ray diffraction data recorded on film $(a=4.081, c=8.162 \AA$; 


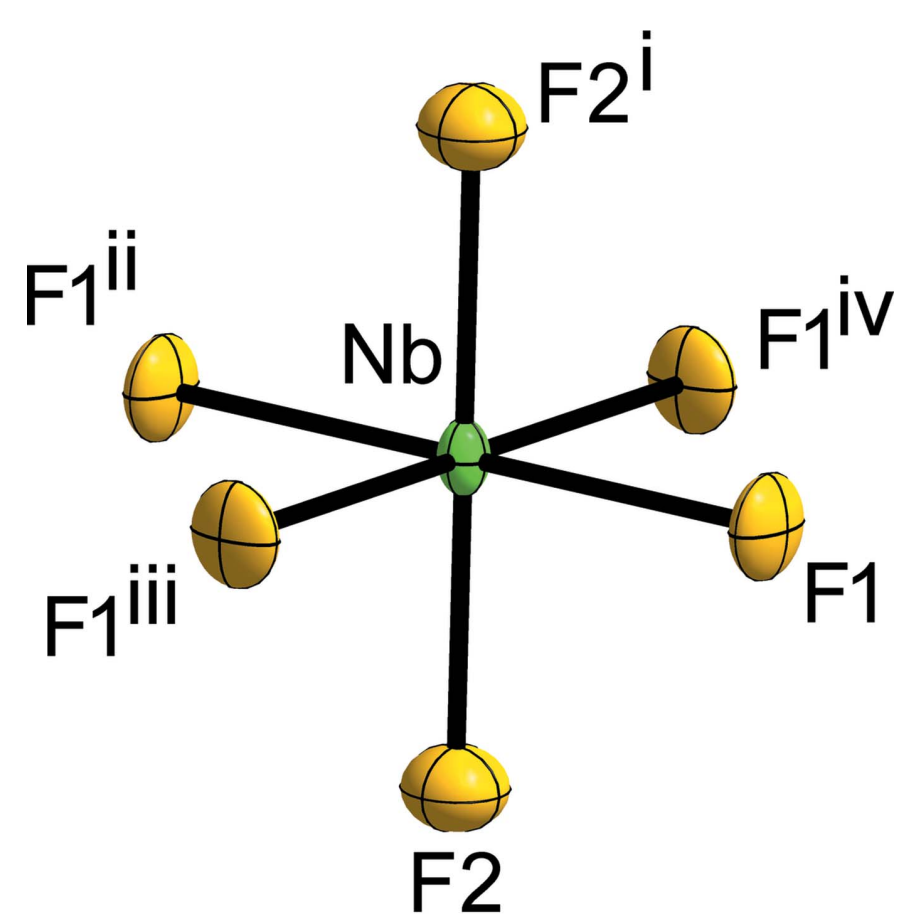

Figure 1

A section of the crystal structure of the title compound displaying the coordination polyhedron around the $\mathrm{Nb}$ atom. Displacement ellipsoids are shown at the $70 \%$ probability level at $293 \mathrm{~K}$. [Symmetry codes: (i) $-x$, $-y,-z$; (ii) $x, y-1, z$; (iii) $-y, x, z$; (iv) $-y+1, x, z$.]

Gortsema \& Didchenko, 1965; $a=4.08$ (3), $c=8.16$ (1) $\AA$; Schäfer et al., 1965).

$\mathrm{NbF}_{4}$ crystallizes in the $\mathrm{SnF}_{4}$ structure type (Hoppe \& Dähne, 1962; Bork \& Hoppe, 1996), which has been discussed extensively and its structural relationship to the $\mathrm{NaCl}$ structure type (Müller, 2013) deduced. The $\mathrm{Nb}$ atom resides on Wyckoff position $2 a$ (site symmetry $4 / \mathrm{mmm}$ ) and is octahedron-like coordinated by six fluorine atoms of which four are bridging to further octahedra, thus corner-sharing connections are obtained. These $\mathrm{Nb}-(\mu-\mathrm{F})$ distances, with the $\mathrm{F} 1$ atoms residing on the $4 c(\mathrm{mmm}$.) position, are observed to be 2.0438 (3) $\AA$ and the $\mathrm{Nb}-\mathrm{F}-\mathrm{Nb}$ angle is $180^{\circ}$ due to spacegroup symmetry. The structure models based on powder diffraction data yielded 2.041 (Gortsema \& Didchenko, 1965) and $2.042 \AA$ (Schäfer et al., 1965) for these $\mathrm{Nb}-\mathrm{F}$ distances. The $\mathrm{Nb}-(\mu-\mathrm{F})$ distance is similar to the respective ones of $\mathrm{NbF}_{5}[2.06$ (2) and 2.07 (2) $\AA$; Edwards, 1964] but shorter than the respective one of $\mathrm{Nb}_{2} \mathrm{~F}_{5}$ [2.1179 (4) ̊; Knoll et al., 2006]. Two fluorine atoms $(\mathrm{F} 2,4 e, 4 \mathrm{~mm})$ of the title compound are not bridging and are trans arranged at the $\mathrm{Nb}$ atom. As expected, the non-bridging $\mathrm{F} 2$ atoms show shorter $\mathrm{Nb}-\mathrm{F}$ distances of 1.8524 (19) $\AA$; these values differ significantly from those of 2.0405 (Gortsema \& Didchenko, 1965) and $2.040 \AA$ (Schäfer et al., 1965). The F2 atoms are surrounded by twelve $\mathrm{F}$ atoms (eight symmetry-equivalent F1 and four F2 atoms) in the shape of a distorted cuboctahedron. A 'central' F2 atom is displaced by $0.24 \AA$ from the center of this cuboctahedron towards the $\mathrm{Nb}$ atom to which it is bound. Hence the expected deviation from $m \overline{3} m\left(O_{\mathrm{h}}\right)$ to $4 / m m m\left(D_{4 \mathrm{~h}}\right)$ symmetry is much more obvious. In comparison to the $\mathrm{Nb}-\mathrm{F}$ distances (non-bridging $\mathrm{F}$-atoms) of $\mathrm{NbF}_{5}$, which are reported to be 1.75 (5) and 1.78 (5) $\AA$ (Edwards, 1964), an elongation is observed. This is attributed to the higher oxidation state of the $\mathrm{Nb}$ atom in $\mathrm{NbF}_{5}$. Fig. 1 shows a section of the crystal structure displaying the coordination polyhedron around the $\mathrm{Nb}$ atom. As in $\mathrm{SnF}_{4}$, infinite layers with Niggli formula ${ }_{\infty}^{2}\left[\mathrm{NbF}_{4 / 2} \mathrm{~F}_{2 / 1}\right]$ are present and extend parallel to the $a b$ plane. The crystal structure is shown in Fig. 2.

\section{Synthesis and crystallization}

Niobium tetrafluoride was synthesized by heating brown $\mathrm{Nb}_{2} \mathrm{~F}_{5}(54,4 \mathrm{mg}, 0,16 \mathrm{mmol})$ to $1273 \mathrm{~K}$ in a sealed niobium tube ( $22 \mathrm{~mm}, 4 \mathrm{~mm}$ i.d., $6 \mathrm{~mm}$ o.d.) which was placed upright in an evacuated sealed silica tube. The heating rate was $20 \mathrm{~K} \mathrm{~h}^{-1}$ and the maximum temperature was held for two days. The niobium ampoule had been charged under nitrogen atmosphere in a glove box and sealed by arc welding. $\mathrm{Nb}_{2} \mathrm{~F}_{5}$ was also synthesized in a niobium ampoule $(33 \mathrm{~mm}, 4 \mathrm{~mm}$ i.d., $6 \mathrm{~mm}$ o.d.) starting from niobium metal and niobium pentafluoride with a heating rate of $16 \mathrm{~K} \mathrm{~h}^{-1}$. The maximum temperature of $1073 \mathrm{~K}$ was held for two days. The ampoules were allowed to cool to room temperature and were opened under inert atmosphere. A powder X-ray diffraction pattern of the green product shows the reflections of $\mathrm{NbF}_{4}, \mathrm{Nb}$ and an yet unidentified phase. It seems that $\mathrm{Nb}_{2} \mathrm{~F}_{5}$ disproportionates to $\mathrm{NbF}_{5}$ and $\mathrm{Nb}$, and by cooling $\mathrm{NbF}_{4}$ is formed. This assumption is supported by the observation that high pressure

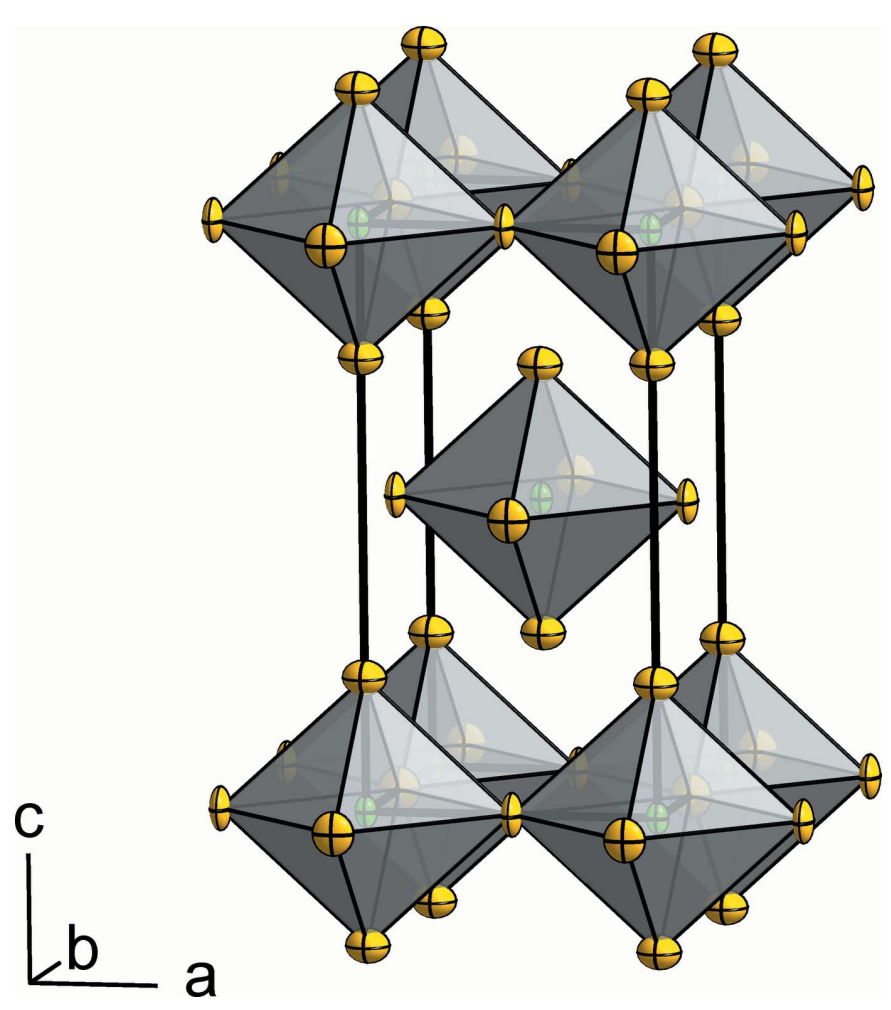

Figure 2

The crystal structure of $\mathrm{NbF}_{4}$ presented as a polyhedron model. Displacement ellipsoids are shown at $70 \%$ probability level at $293 \mathrm{~K}$. 
inside the ampoule blew it up. The pressure is likely induced by gaseous $\mathrm{NbF}_{5}$, and the disproportionation of $\mathrm{Nb}_{2} \mathrm{~F}_{5}$ to $\mathrm{Nb}$ and $\mathrm{NbF}_{5}$ is known from the literature (Schäfer et al., 1965). A selected single crystal of $\mathrm{NbF}_{4}$ was investigated using X-ray diffraction and diffraction data measured at room temperature.

\section{Refinement}

As a starting model for the structure refinement, the atomic coordinates of the $\mathrm{SnF}_{4}$ structure type were used. Crystal data, data collection and structure refinement details are summarized in Table 1. One reflection (112) was omitted from the refinement as it was affected by the primary beam stop.

\section{Acknowledgements}

FK thanks the DFG for his Heisenberg-Professorship, the X-ray facilities of Dr Harms for their services, Professor Dr B. Harbrecht for the kind donation of niobium metal, and Solvay for the generous donations of fluorine.

\section{References}

Bork, M. \& Hoppe, R. (1996). Z. Anorg. Allg. Chem. 622, 1557-1563. Brandenburg, K. (2015). DIAMOND. Crystal Impact GbR, Bonn, Germany.

Chassaing, J. \& Bizot, D. (1980). J. Fluor. Chem. 16, 451-459.

Dickson, F. E. (1969). J. Inorg. Nucl. Chem. 31, 2636-2638.

Edwards, A. J. (1964). J. Chem. Soc. pp. 3714-3718.

Gortsema, F. P. \& Didchenko, R. (1965). Inorg. Chem. 4, 182-186.

Hoppe, R. \& Dähne, W. (1962). Naturwissenschaften, 49, 254-255.

Knoll, R., Sokolovski, J., BenHaim, Y., Shames, A. I., Goren, S. D., Shaked, H., Thépot, J.-Y., Perrin, C. \& Cordier, S. (2006). Physica $B, \mathbf{3 8 1}, 47-52$.

Müller, U. (2013). In Symmetry Relationships between Crystal Structures. Oxford University Press.
Table 1

Experimental details.

\begin{tabular}{|c|c|}
\hline \multicolumn{2}{|l|}{ Crystal data } \\
\hline Chemical formula & $\mathrm{NbF}_{4}$ \\
\hline$M_{\mathrm{r}}$ & 168.91 \\
\hline Crystal system, space group & Tetragonal, $I 4 / \mathrm{mmm}$ \\
\hline Temperature $(\mathrm{K})$ & 293 \\
\hline$a, c(\AA)$ & $4.0876(5), 8.1351(19)$ \\
\hline$V\left(\AA^{3}\right)$ & $135.93(5)$ \\
\hline$Z$ & 2 \\
\hline Radiation type & Мо $K \alpha$ \\
\hline$\mu\left(\mathrm{mm}^{-1}\right)$ & 4.32 \\
\hline Crystal size $(\mathrm{mm})$ & $0.06 \times 0.04 \times 0.01$ \\
\hline \multicolumn{2}{|l|}{ Data collection } \\
\hline Diffractometer & Stoe IPDS 2T \\
\hline Absorption correction & $\begin{array}{l}\text { Integration }(X-R E D 32 \text { and } \\
\quad X \text {-SHAPE; Stoe \& Cie, 2009) }\end{array}$ \\
\hline$T_{\min }, T_{\max }$ & $0.664,0.925$ \\
\hline $\begin{array}{l}\text { No. of measured, independent and } \\
\text { observed }[I>2 \sigma(I)] \text { reflections }\end{array}$ & $1392,167,167$ \\
\hline$R_{\text {int }}$ & 0.057 \\
\hline$(\sin \theta / \lambda)_{\max }\left(\AA^{-1}\right)$ & 0.944 \\
\hline \multicolumn{2}{|l|}{ Refinement } \\
\hline$R\left[F^{2}>2 \sigma\left(F^{2}\right)\right], w R\left(F^{2}\right), S$ & $0.014,0.032,0.98$ \\
\hline No. of reflections & 167 \\
\hline No. of parameters & 10 \\
\hline$\Delta \rho_{\max }, \Delta \rho_{\min }\left(\mathrm{e} \AA^{-3}\right)$ & $0.69,-0.58$ \\
\hline
\end{tabular}

Computer programs: $X$-AREA (Stoe \& Cie, 2011), X-RED32 (Stoe \& Cie, 2009), SHELXL2014 (Sheldrick, 2015) and DIAMOND (Brandenburg, 2015).

Schäfer, H., Bauer, D., Beckmann, W., Gerken, R., NiederVahrenholz, H.-G., Niehues, K.-J. \& Scholz, H. (1964). Naturwissenschaften, 51, 241-241.

Schäfer, H., von Schnering, H. G., Niehues, K.-J. \& NiederVahrenholz, H. G. (1965). J. Less-Common Met. 9, 95-104.

Sheldrick, G. M. (2015). Acta Cryst. C71, 3-8.

Stoe \& Cie (2009). X-RED32 and X-SHAPE. Stoe \& Cie GmbH, Darmstadt, Germany.

Stoe \& Cie (2011). X-AREA. Stoe \& Cie GmbH, Darmstadt, Germany. 


\section{supporting information}

Acta Cryst. (2016). E72, 1211-1213 [https://doi.org/10.1107/S2056989016012081]

\section{Redetermination of the crystal structure of $\mathrm{NbF}_{4}$}

\section{Jascha Bandemehr, Matthias Conrad and Florian Kraus}

\section{Computing details}

Data collection: $X$-AREA (Stoe \& Cie, 2011); cell refinement: $X$-AREA (Stoe \& Cie, 2011); data reduction: $X$-RED32 (Stoe \& Cie, 2009); program(s) used to refine structure: SHELXL2014 (Sheldrick, 2015); molecular graphics: DIAMOND (Brandenburg, 2015); software used to prepare material for publication: SHELXL2014 (Sheldrick, 2015).

Niobium(IV) tetrafluoride

Crystal data

$\mathrm{NbF}_{4}$

$M_{r}=168.91$

Tetragonal, $14 / \mathrm{mmm}$

$a=4.0876(5) \AA$

$c=8.1351(19) \AA$

$V=135.93(5) \AA^{3}$

$Z=2$

$F(000)=154$

\section{Data collection}

Stoe IPDS 2T diffractometer

Radiation source: sealed X-ray tube, 12 x 0.4 $\mathrm{mm}$ long-fine focus

Plane graphite monochromator Detector resolution: 6.67 pixels $\mathrm{mm}^{-1}$ rotation method scans

Absorption correction: integration

(X-RED32 and X-SHAPE; Stoe \& Cie, 2009)

Refinement

Refinement on $F^{2}$

Least-squares matrix: full

$R\left[F^{2}>2 \sigma\left(F^{2}\right)\right]=0.014$

$w R\left(F^{2}\right)=0.032$

$S=0.98$

167 reflections

10 parameters

0 restraints

Primary atom site location: isomorphous structure methods
$D_{\mathrm{x}}=4.127 \mathrm{Mg} \mathrm{m}^{-3}$

Mo $K \alpha$ radiation, $\lambda=0.71073 \AA$

Cell parameters from 2534 reflections

$\theta=5.0-42.2^{\circ}$

$\mu=4.32 \mathrm{~mm}^{-1}$

$T=293 \mathrm{~K}$

Plate, green

$0.06 \times 0.04 \times 0.01 \mathrm{~mm}$

$T_{\min }=0.664, T_{\max }=0.925$

1392 measured reflections

167 independent reflections

167 reflections with $I>2 \sigma(I)$

$R_{\text {int }}=0.057$

$\theta_{\max }=42.1^{\circ}, \theta_{\min }=5.0^{\circ}$

$h=-7 \rightarrow 5$

$k=-7 \rightarrow 7$

$l=-14 \rightarrow 15$

Secondary atom site location: isomorphous structure methods

$w=1 /\left[\sigma^{2}\left(F_{\mathrm{o}}^{2}\right)+(0.025 P)^{2}\right]$

where $P=\left(F_{\mathrm{o}}{ }^{2}+2 F_{\mathrm{c}}{ }^{2}\right) / 3$

$(\Delta / \sigma)_{\max }<0.001$

$\Delta \rho_{\max }=0.69 \mathrm{e} \AA^{-3}$

$\Delta \rho_{\min }=-0.58$ e $\AA^{-3}$

Extinction correction: SHELXL2014

(Sheldrick, 2015),

$\mathrm{Fc}^{*}=\mathrm{kFc}\left[1+0.001 \times \mathrm{Fc}^{2} \lambda^{3} / \sin (2 \theta)\right]^{-1 / 4}$

Extinction coefficient: 0.026 (5) 


\section{Special details}

Geometry. All esds (except the esd in the dihedral angle between two 1.s. planes) are estimated using the full covariance matrix. The cell esds are taken into account individually in the estimation of esds in distances, angles and torsion angles; correlations between esds in cell parameters are only used when they are defined by crystal symmetry. An approximate (isotropic) treatment of cell esds is used for estimating esds involving l.s. planes.

Fractional atomic coordinates and isotropic or equivalent isotropic displacement parameters $\left(\AA^{2}\right)$

\begin{tabular}{lllll}
\hline & $x$ & $y$ & $z$ & $U_{\text {iss }} / U_{\text {eq }}$ \\
\hline $\mathrm{Nb}$ & 0.0000 & 0.0000 & 0.0000 & $0.00798(9)$ \\
$\mathrm{F} 1$ & 0.0000 & 0.5000 & 0.0000 & $0.0167(3)$ \\
$\mathrm{F} 2$ & 0.0000 & 0.0000 & $0.2277(2)$ & $0.0209(3)$ \\
\hline
\end{tabular}

Atomic displacement parameters $\left(\AA^{2}\right)$

\begin{tabular}{lllllll}
\hline & $U^{11}$ & $U^{22}$ & $U^{33}$ & $U^{12}$ & $U^{13}$ & $U^{23}$ \\
\hline $\mathrm{Nb}$ & $0.00583(10)$ & $0.00583(10)$ & $0.01230(11)$ & 0.000 & 0.000 & 0.000 \\
$\mathrm{~F} 1$ & $0.0211(7)$ & $0.0056(5)$ & $0.0235(6)$ & 0.000 & 0.000 & 0.000 \\
$\mathrm{~F} 2$ & $0.0239(5)$ & $0.0239(5)$ & $0.0149(5)$ & 0.000 & 0.000 & 0.000 \\
\hline
\end{tabular}

Geometric parameters $\left(\AA,{ }^{o}\right)$

\begin{tabular}{|c|c|c|c|}
\hline $\mathrm{Nb}-\mathrm{F} 2^{\mathrm{i}}$ & $1.8524(19)$ & $\mathrm{Nb}-\mathrm{F} 1^{\mathrm{iii}}$ & $2.0438(3)$ \\
\hline $\mathrm{Nb}-\mathrm{F} 2$ & $1.8524(19)$ & $\mathrm{Nb}-\mathrm{F} 1^{\mathrm{iv}}$ & $2.0438(3)$ \\
\hline $\mathrm{Nb}-\mathrm{F} 1$ & $2.0438(3)$ & $\mathrm{F} 1-\mathrm{Nb}^{\mathrm{v}}$ & $2.0438(3)$ \\
\hline $\mathrm{Nb}-\mathrm{F} 1^{\mathrm{ii}}$ & $2.0438(3)$ & & \\
\hline $\mathrm{F} 2^{\mathrm{i}}-\mathrm{Nb}-\mathrm{F} 2$ & 180.0 & $\mathrm{~F} 1-\mathrm{Nb}-\mathrm{F} 1^{\mathrm{iii}}$ & 90.0 \\
\hline $\mathrm{F} 2 \mathrm{i}-\mathrm{Nb}-\mathrm{F} 1$ & 90.0 & 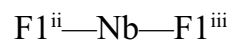 & 90.0 \\
\hline $\mathrm{F} 2-\mathrm{Nb}-\mathrm{F} 1$ & 90.0 & $\mathrm{~F} 2^{\mathrm{i}}-\mathrm{Nb}-\mathrm{F} 1^{\mathrm{iv}}$ & 90.0 \\
\hline $\mathrm{F} 2^{\mathrm{i}}-\mathrm{Nb}-\mathrm{F} 1^{\mathrm{ii}}$ & 90.0 & $\mathrm{~F} 2-\mathrm{Nb}-\mathrm{F} 1^{\mathrm{iv}}$ & 90.0 \\
\hline $\mathrm{F} 2-\mathrm{Nb}-\mathrm{F} 1^{\mathrm{ii}}$ & 90.0 & $\mathrm{~F} 1-\mathrm{Nb}-\mathrm{F} 1^{\mathrm{iv}}$ & 90.0 \\
\hline $\mathrm{F} 1-\mathrm{Nb}-\mathrm{F} 1^{\mathrm{ii}}$ & 180.0 & $\mathrm{~F} 1^{\mathrm{ii}-}-\mathrm{Nb}-\mathrm{F} 1^{\mathrm{iv}}$ & 90.0 \\
\hline $\mathrm{F} 2^{\mathrm{i}}-\mathrm{Nb}-\mathrm{F} 1^{\mathrm{iii}}$ & 90.0 & 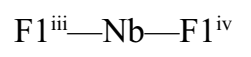 & 180.0 \\
\hline $\mathrm{F} 2-\mathrm{Nb}-\mathrm{F} 1^{\mathrm{iii}}$ & 90.0 & $\mathrm{Nb}^{\mathrm{v}}-\mathrm{F} 1-\mathrm{Nb}$ & 180.0 \\
\hline
\end{tabular}

Symmetry codes: (i) $-x,-y,-z$; (ii) $x, y-1, z$; (iii) $-y, x, z$; (iv) $-y+1, x, z$; (v) $x, y+1, z$. 